\title{
Role of Oxidative Stress and Adenosine Nucleotides in the Liver of Aging Rats
}

\author{
F. MÁRMOL ${ }^{1}$, J. SÁNCHEZ ${ }^{1}$, D. LÓPEZ ${ }^{2}$, N. MARTÍNEZ ${ }^{2}$, C. XAUS $^{3}$, C. PERALTA $^{4}$, \\ J. ROSELLÓ-CATAFAU ${ }^{3}$, M. T. MITJAVILA ${ }^{2}$, P. PUIG-PARELLADA ${ }^{1}$ \\ ${ }^{1}$ Pharmacology Unit, Faculty of Medicine, IDIBAPS, University of Barcelona, Barcelona, Spain, \\ ${ }^{2}$ Department of Physiology, Faculty of Biology, University of Barcelona, Barcelona, Spain, \\ ${ }^{3}$ Hepatology Unit, IDIBAPS, Barcelona, Spain, ${ }^{4}$ Section of Biological Aggression and Mechanism \\ of Defense, IDIBAPS, Barcelona, Spain
}

Received February 18, 2009

Accepted September 1, 2009

On-line November 20, 2009

\begin{abstract}
Summary
We studied the response of several parameters related to oxidative stress in the liver of aging rats. Male Wistar rats aged $1.5,3,18$ and 24 months were used. Livers showed an increase in superoxide anion $\left(\mathrm{O}_{2}^{-}\right)$concentration at 1.5 and 18 months of age compared to the 3-month-old group; a decrease in superoxide dismutase (SOD) was seen at 1.5 months and catalase concentrations remained unaltered throughout the aging process. Nitric oxide (NO) progressively declined with age; a significant decrease was particularly apparent at 18 and 24 months of age. Thiobarbituric acid reactive substances (TBARS) decreased significantly at 1.5 months, whereas it increased at 18 and 24 months of age. Concentrations of prostaglandin $E_{2}$ $\left(\mathrm{PGE}_{2}\right)$, and adenine nucleotides, and their metabolites, remained unchanged throughout the aging process. Although the mitochondrial damage caused by oxidative stress can result in reduced ATP production and compromised cell function, our results on adenosine nucleotides and their metabolites support the notion that the integrity of mitochondria and enzymatic activity remain mostly unchanged with aging. In conclusion, we observed a significant decrease in the levels of NO in the older groups of rats and hence in its antioxidant activity. This could explain the observed increase in lipid peroxides which suggests an important role for NO in oxidative stress in the liver of older rats.
\end{abstract}

\section{Key words}

Adenosine nucleotides $\bullet$ Liver $\bullet$ Nitric oxide • Oxidative stress • Rats

\section{Corresponding author}

P. Puig-Parellada, Unitat de Farmacologia, Facultat de Medicina, Casanova 143, 08036 Barcelona, Spain. Fax: +34 934035881. E-mail: ppuigp@ub.edu

\section{Introduction}

Aging can be defined as an intrinsic biological process from which there is no way out. It is characterized by the degeneration of basic functions in the late or post-reproductive phase of all multicellular organisms (Sohal 2002, Ehrenbrink et al. 2006).

The extent of cellular damage and aging is related to a balance between the production of oxidants and their removal by the antioxidant system. Superoxide anions $\left(\mathrm{O}_{2}^{-}\right)$are the first oxygen free radical generated and are formed by the univalent reduction of oxygen. This reduction is mediated by several enzyme systems, including NADPH oxidase, xanthine oxidase and cyclooxygenase. In healthy livers, hepatocytes produce small amounts of reactive oxygen species (ROS) and Kupffer cells, the resident macrophages in the liver, release ROS in response to bacterial stimuli. Hepatic stellate cells contain a non-phagocytic form of NADPH oxidase. This form is constitutively active, producing relatively low levels of ROS under basal conditions (De Minicis et al. 2006). ROS is also involved in the pathophysiology of inflammatory liver diseases (Jaeschke 2000, De Minicis et al. 2006). 
Steady-state levels of $\mathrm{O}_{2}^{-}$are dependent on both the production rate and the activity of the various superoxide dismutase (SOD) isoforms (Faraci and Didion 2004). The $\mathrm{O}_{2}^{-}$generated is captured by SOD and metabolized to hydrogen peroxide $\left(\mathrm{H}_{2} \mathrm{O}_{2}\right)$ in a cellular antioxidant reaction; catalase and glutathione peroxidase then detoxify the $\mathrm{H}_{2} \mathrm{O}_{2}$ generated. Lipid peroxides which are expressed as thiobarbituric acid reactive substances (TBARS), reflect a condition of oxidative stress. Nitric oxide (NO) is a free radical that has a beneficial effect on the liver by protecting it against both tissue injury and the cytotoxic effects of invading microorganisms, parasites, and tumor cells. Thus, NO may prevent liver tissue damage caused by oxidative stress (Suzuki et al. 1995). Prostaglandin $\mathrm{E}_{2} \quad\left(\mathrm{PGE}_{2}\right)$ is generated through the activation of constitutive cyclooxygenase-1 (COX-1) in hepatocytes and plays a crucial role in liver pathophysiology through essentially hepatoprotective functions such as inhibiting the generation of ROS, preventing leukocyte migration, improving hepatic insulin and lipid metabolism and regulating the production of inflammatory cytokines (Park et al. 1986, Hossain et al. 2006).

Mitochondria are the main cell components responsible for events involving oxidative stress. Thus, a vicious cycle may occur in which damaged mitochondria produce progressively greater amounts of ROS, leading, in turn, to progressively greater damage to mitochondrial, cytosolic and nuclear compartments and finally resulting in dysfunctional or defective mitochondria, which is the basis of the mitochondrial theory of aging (Miquel et al. 1980, Harper et al. 2004). The mitochondrial damage caused by oxidative stress could result in reduced ATP production and compromised cell function (Van Remmen and Richardson 2001). These classical considerations together with a recent discussion on the weaknesses of the mitochondrial theory of aging (Krause 2007) and the data that question whether the in vitro studies of oxidative damage to mitochondria reflect what occurs in vivo (Van Remmen and Richardson 2001) prompted us to determine the concentrations of adenosine nucleotides, nucleosides and purine bases in the liver of aging rats.

Adenosine nucleosides (adenosine and inosine) have an anti-inflammatory potential, which is based mainly on the inhibition of pro-inflammatory cytokines and the release of free radicals. Increased purine nucleosides are found in ischemic and inflammatory tissues and these compounds prevent oxidative damage to DNA and protect mice against $\gamma$-radiation-induced death
(Gudkov et al. 2006, Schneider et al. 2006).

Here we studied the occurrence of oxidative stress in rats aged 1.5, 3, 18 and 24 months. These represent a broad range of ages, from very young to old rats. The presence of oxidative stress was determined on the basis of the production of $\mathrm{O}_{2}^{-}$, two antioxidant enzymes: SOD and catalase, and TBARS as an indicator of lipid peroxidation. The production of two hepatoprotective agents, $\mathrm{PGE}_{2}$ and $\mathrm{NO}$, was also examined as were the concentrations of adenosine nucleotides and their metabolites caused by the involvement of mitochondria in oxidative stress. The rats were not manipulated; age was the only parameter considered.

\section{Materials and Methods}

\section{Animals and sample preparation}

Male Wistar rats (Harlan Interfauna Iberica S.L.) aged 1.5, 3, 18 and 24 months were used. All the animals were fed standard laboratory chow and had access to water ad libitum.

Experiments were conducted in accordance with the Guide for the Care of Laboratory Animals (EEC Council Directive 86/609/EEC). All the studies were approved by the Research and Development and Animal Care Committee of the University of Barcelona.

The rats were anesthetized with sodium pentobarbital and killed by exsanguination. The liver was perfused with $20 \mathrm{ml}$ of saline through the suprahepatic vein. The liver was then excised and after removing the border, the main lobe was cut into fragments $3 \mathrm{~mm}$ wide and $10 \mathrm{~mm}$ long. These samples were frozen in liquid nitrogen and kept at $-80{ }^{\circ} \mathrm{C}$. All the ex vivo assays were performed in duplicate in 6 different animals. The 3-month-old rats were used for comparison with the other age groups.

\section{Superoxide anion assay}

The technique developed by Pagano et al. (1995) was used. Liver samples (150-160 mg) from each rat were defrosted by immersion in a Tyrode solution (in $\mathrm{mM}, \mathrm{NaCl} 137 ; \mathrm{KCl} 3 ; \mathrm{CaCl}_{2}$ 1.36; $\mathrm{MgSO}_{4}$ 1.2; $\mathrm{NaH}_{2} \mathrm{PO}_{4}$ 0.5; $\mathrm{NaHCO}_{3} 12$; glucose 5.5) at $4{ }^{\circ} \mathrm{C}$. Each experiment was performed in duplicate. The fragments were incubated in $1 \mathrm{ml}$ Tyrode solution for $30 \mathrm{~min}$ at $37{ }^{\circ} \mathrm{C}$ with continuous air bubbling and then rinsed with Tyrode solution. The samples were placed in $1 \mathrm{ml}$ of the same solution in a luminescence cuvette containing a 
non-redox cycling concentration of lucigenin $(5 \mu \mathrm{M})$ (Sigma). The cuvettes were then placed in a luminometer (Bio-Orbit 1251, Turku, Finland) and maintained at $37^{\circ} \mathrm{C}$. The luminometer was set to report arbitrary units of emitted light, and integrated over a 30 -s interval for 3 min. A blank Tyrode solution gave low and constant readings that were comparable to those obtained from a blank lucigenin solution. The results are expressed as units of luminescence $/ \mathrm{min} / \mathrm{g}$ tissue. The possible differences in the luminescence response to fresh and frozen samples of liver were also examined. The behavior of both types of samples was similar (data not shown).

\section{Thiobarbituric acid reactive substances}

Liver samples were homogenized with $120 \mathrm{mM}$ $\mathrm{KCl}(1 \mathrm{ml} / 50 \mathrm{mg}$ of wet tissue) and $50 \mu \mathrm{l}$ of $0.5 \%$ butylated hydroxytoluene (BHT). After centrifugation at $1000 \mathrm{x} \mathrm{g}$ for $10 \mathrm{~min}, 100 \mu \mathrm{l}$ of supernatant was collected. We then added $100 \mu \mathrm{l}$ trichloroacetic acid (TCA) $40 \%$ (w/v) (Aldrich), and $400 \mu \mathrm{l}$ of thiobarbituric acid (TBA) $0.67 \%(\mathrm{w} / \mathrm{v})($ Merck) in $0.05 \mathrm{M} \mathrm{NaOH}$ was added to the supernatant. The mixture was then heated in a water bath at $97{ }^{\circ} \mathrm{C}$ for 10 min using a glass ball as a condenser. After cooling, $200 \mu \mathrm{l}$ of glacial acetic acid and $400 \mu \mathrm{l}$ of chloroform were added and shaken with a vortex. After centrifugation at $1700 \mathrm{xg}$ for $30 \mathrm{~min}$, the organic layer was collected for spectrophotometric measurements at $530 \mathrm{~nm}$. The results are expressed as ng TBARS/mg protein. A standard curve was drawn by preparing a malondialdehyde (MDA) solution (10 mM) by hydrolysis of 1,1,3,3-tetraethoxypropane (Sigma) with hydrochloric acid. Protein quantification was performed following the method described by Lowry et al. (1951) using serum albumin as standard.

\section{Antioxidant enzymes assays}

Liver samples were homogenized by Polytron (Kinematica, AG, Littau, Switzerland) in $2 \mathrm{ml}$ of phosphate buffer $(50 \mathrm{mM}, \mathrm{pH} 7.0)$ containing $10 \mathrm{mM}$ ethylenediaminetetraacetic acid (EDTA), $0.13 \mathrm{mM}$ BHT, and $0.13 \mathrm{mM}$ desferrioxamine (iron chelator) to minimize oxidation during the homogenization. The minced tissue/buffer mixture was homogenized in two passes of $20 \mathrm{~s}$ at $37{ }^{\circ} \mathrm{C}$. The homogenates were centrifuged at $300 \mathrm{x} \mathrm{g}$ for $10 \mathrm{~min}$ at $4{ }^{\circ} \mathrm{C}$ to remove cellular debris. The supernatant was then collected to analyse SOD and catalase antioxidant enzyme activity.

SOD activity was assayed by the inhibition of pyrogallol autooxidation (Marklund 1985). We then added $1.2 \mathrm{ml}$ of ethanol-chloroform (5:3 v/v) to $750 \mu \mathrm{l}$ of supernatant. After centrifugation at $3400 \mathrm{x}$ g for $5 \mathrm{~min}$ at $4{ }^{\circ} \mathrm{C}$, several volumes of the supernatant were added to $25 \mu \mathrm{l}$ of Tris-HCl. Finally, $20 \mu \mathrm{l}$ of pyrogallol (Sigma) was added to start the reaction. Results are expressed as units/g tissue (one unit induces an inhibition of $50 \%$ pyrogallol auto-oxidation).

Catalase activity was assayed by $\mathrm{H}_{2} \mathrm{O}_{2}$ consumption, following Aebi's (1984) method and modified by Pieper et al. (1995). Briefly, ethanol was added $(1: 100 \mathrm{v} / \mathrm{v})$ to the supernatants and incubated for $30 \mathrm{~min}$ in an ice bath. We then added $1 \%$ Triton X-100 $(1: 10 \mathrm{v} / \mathrm{v})($ Sigma) to the homogenates. This solution was placed in an ice bath for an additional $15 \mathrm{~min} .500 \mu \mathrm{l}$ of this solution was placed into a glass cuvette and $250 \mu \mathrm{l}$ of $30 \mathrm{mM} \mathrm{H}_{2} \mathrm{O}_{2}$ (Sigma) in a phosphate buffer was then added to start the reaction. After $15 \mathrm{~s}$ the absorbance at $240 \mathrm{~nm}$ was read every $15 \mathrm{~s}$ for $45 \mathrm{~s}$. The first-order reaction rate $(\mathrm{k})$ of $\mathrm{H}_{2} \mathrm{O}_{2}$ consumption by catalase was calculated and the results are expressed in $\mathrm{k} / \mathrm{g}$ tissue. The assay was performed at $25^{\circ} \mathrm{C}$.

\section{Prostaglandin $E_{2}$ assay}

Liver samples were incubated for $30 \mathrm{~min}$ at $37^{\circ} \mathrm{C}$. After centrifugation the supernatant was stored at $-80{ }^{\circ} \mathrm{C}$ until the day of the analysis. The production of $\mathrm{PGE}_{2}$ was determined with a $\mathrm{PGE}_{2}$ monoclonal antibody $\left(\mathrm{PGE}_{2}\right.$ EIA kit, Cayman Chemical Co) following the manufacturer's protocol. The results are expressed as $\mathrm{pg} / \mathrm{mg}$ protein.

\section{Nitric oxide assay}

NO was detected as described by Vanin (1999). Liver samples were preincubated at $37{ }^{\circ} \mathrm{C}$ for $20 \mathrm{~min}$ in Ringer solution (pH 7.4) and exposed to the spin trapping agents diethyldithiocarbamic acid (DETC, $5 \mathrm{nmol} / \mathrm{l}$ ) (Aldrich) and $\mathrm{FeSO}_{4}(50 \mu \mathrm{mol} / \mathrm{l})$ for $30 \mathrm{~min}$. Finally, the samples were weighed, frozen in liquid nitrogen and stored at $-80{ }^{\circ} \mathrm{C}$ for later ESR analysis. The ESRdetectable paramagnetic complex was evaluated in a Bruker 300E spectrometer (Bruker Instruments, Billerica, MA). Given the complex, the signal corresponded to the difference in intensity between a maximum at 3440 [G] and a minimum at 3470 [G]. A standard curve of Fe-NODETC was generated by diethylamine NONOate (Cayman) $(10 \mathrm{nmol} / \mathrm{l}$ to $100 \mu \mathrm{mol} / \mathrm{l})$. This curve was used to extrapolate the Fe-NO-DETC signal and also to estimate the linearity of the assay. Results are expressed as relative intensity units/mg tissue. 
Adenosine nucleotide assay

Liver samples were placed in 10 volumes of $3.6 \% \mathrm{HClO}_{4}$ and then immediately homogenized. Following homogenization, tissues were extracted for $30 \mathrm{~min}$ at $0.5{ }^{\circ} \mathrm{C}$ and then centrifuged at $850 \mathrm{x}$ g for $15 \mathrm{~min}$. Supernatants were adjusted to $\mathrm{pH}$ 6.0-6.5 and centrifuged at $14000 \mathrm{x}$ g. Then, we injected $50 \mu \mathrm{l}$ of the supernatant into a Waters 717 Plus Autosampler for liquid chromatography. Nucleotide profiles were obtained using a reversed-phase Spherisorb ODS column (column $\mathrm{C}_{18}, 5 \mu \mathrm{m}$ particle size, $15 \times 0.4 \mathrm{~cm}$; Teknokroma, Sant Cugat, Spain) coupled to a 600 HPLC system (Waters, Milford, MA) equipped with a Waters 996 Photodiode Array Detector. The absorbance was monitored at $254 \mathrm{~nm}$. Nucleotide separation was allowed to proceed in an isocratic fashion with $100 \mathrm{mmol} / \mathrm{l}$ ammonium phosphate (pH 5.5), until the point when ATP, ADP, hypoxanthine, xanthine, and AMP were separated. At this point, a mixture of water-methanol (96:4) was introduced into the column, thereby eluting inosine. Another mixture of water-methanol (60:40) was introduced after inosine in order to elute adenosine. Calibration chromatograms were generated for the following standards by injecting $50 \mu \mathrm{l}$ of a mixture of known concentrations: ATP, ADP, AMP, adenosine, inosine, hypoxanthine, and xanthine (Sigma). The profiles were processed by a Millennium 32 system (Waters, Milford, MA). The results are expressed as $\mathrm{pmol} / \mathrm{mg}$ tissue.

\section{Statistical analysis}

All experiments were carried out at least in duplicate. Every age group consisted of 6 rats. One-way analysis of variance (ANOVA) was performed and Dunnett's post-hoc test was used to compare all the groups against the 3-month-old group. Statistical analyses were performed using the InStat 3.0 program. The results are expressed as mean \pm S.E.M. Linear correlation tests were also performed. Differences of $\mathrm{p}<0.05$ were considered significant.

\section{Results}

One-way ANOVA revealed a significant effect of aging on $\mathrm{O}_{2}^{-}$production $(\mathrm{p}<0.001)$, $\mathrm{NO}(\mathrm{p}<0.001)$, TBARS $(\mathrm{p}<0.001)$ and SOD $(\mathrm{p}<0.05)$, whereas age did not significantly affect the levels of catalase, $\mathrm{PGE}_{2}$, adenosine nucleotides, adenosine nucleosides or purine bases.

We examined the production of $\mathrm{O}_{2}^{-}-$the first

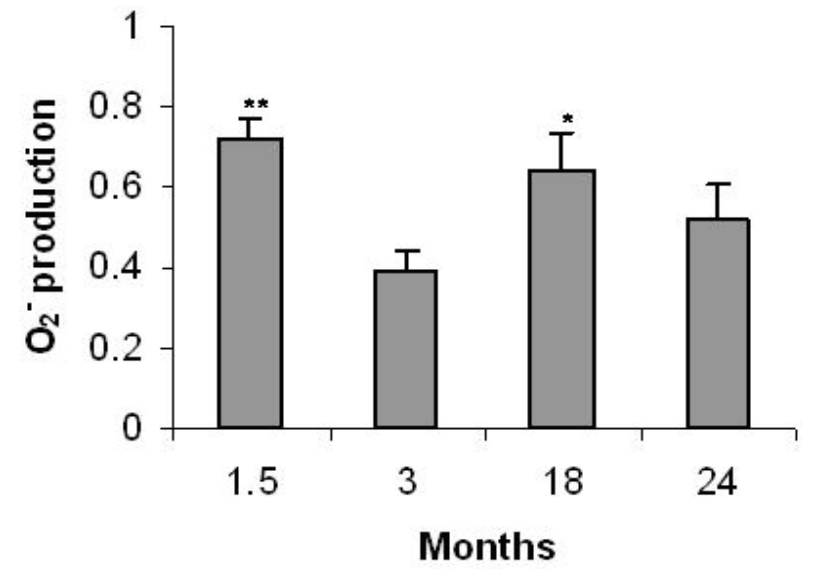

Fig. 1. Effects of aging (1.5 - 24 months) on superoxide anion $\left(\mathrm{O}_{2}{ }^{-}\right)$production in rat liver. Results are expressed as luminescence units $/ \mathrm{min} / \mathrm{g}$ tissue. Values are shown as mean \pm S.E.M. ( $n=6$ per group). ${ }^{*} \mathrm{p}<0.05,{ }^{* *} \mathrm{p}<0.01$ vs. 3 -month-old group.

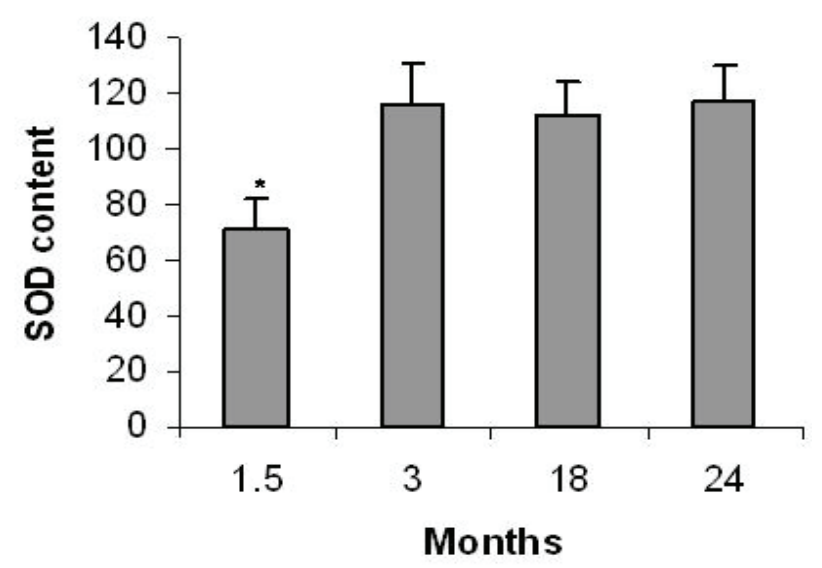

Fig. 2. Effects of aging (1.5 - 24 months) on superoxide dismutase (SOD) content in rat liver. Results are expressed as units $/ g$ tissue. Values are shown as mean \pm S.E.M. $(n=6$ per group). ${ }^{*} p<0.05$ vs. 3-month-old group.

ROS generated in the univalent reduction of oxygen. Our results show significantly higher $\mathrm{O}_{2}{ }^{-}$production at 1.5 $(82 \%, \mathrm{p}<0.01)$ and at 18 months of age $(63 \%, \mathrm{p}<0.05)$ compared to the 3-month-old group (Fig. 1). The content of SOD, which is the main enzyme responsible for maintaining the $\mathrm{O}_{2}^{-}$homeostasis, showed a significant decrease $(38 \%, \mathrm{p}<0.05)$ only when the results for the 1.5 -month-old group were compared with the 3-monthold rats. All other age groups were unaltered (Fig. 2).

The univalent reduction of $\mathrm{O}_{2}^{-}$gave rise to $\mathrm{H}_{2} \mathrm{O}_{2}$ a stable metabolite that can generate hydroxyl radicals in the presence of divalent metals. This metabolite was neutralized by the catalase enzyme. The activity of catalase enzyme in the liver did not significantly change throughout aging (Fig. 3). 


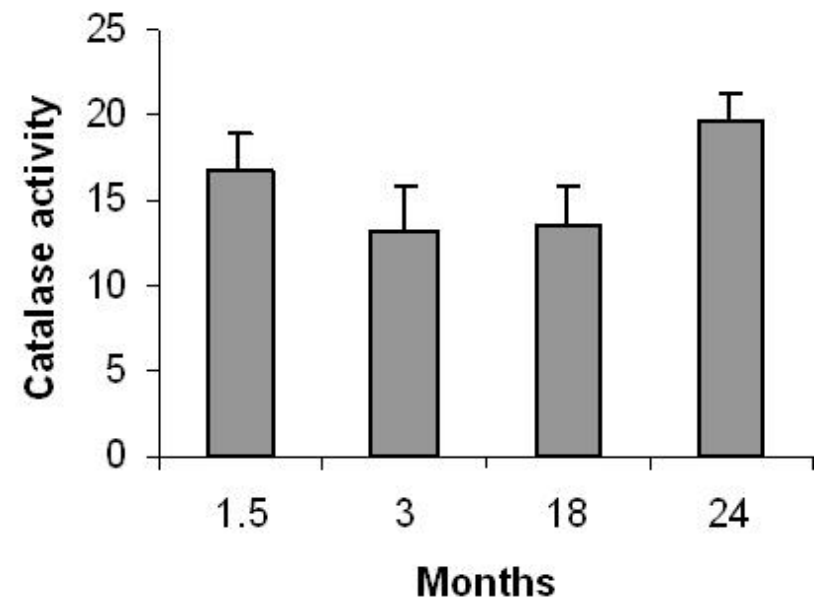

Fig. 3. Effects of aging (1.5 - 24 months) on catalase activity in rat liver. Results are expressed as $\mathrm{k} / \mathrm{g}$ tissue. Values are shown as mean \pm S.E.M. ( $n=6$ per group).

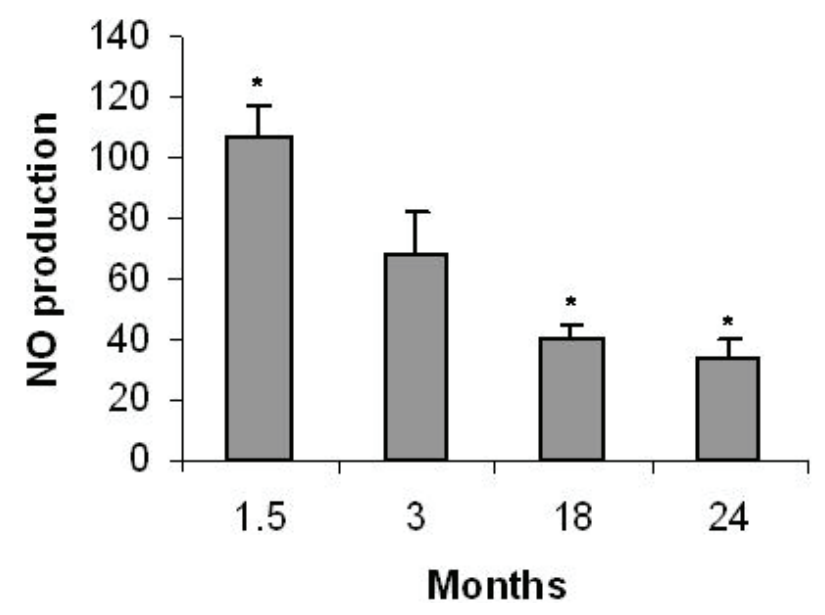

Fig. 4. Effects of aging (1.5 - 24 months) on nitric oxide (NO) production in rat liver. Results are expressed as units/mg tissue. Values are shown as mean \pm S.E.M. $\left(n=6\right.$ per group). ${ }^{*} p<0.05$ vs. 3-month-old group.

The cytoprotective action of $\mathrm{NO}$ on liver prompted us to address its production throughout aging. NO production progressively decreased over time. When the results for the distinct age groups were compared with the 3-month-old rats, a significant increase at 1.5 months $(40 \%, \mathrm{p}<0.05)$ and a decrease at 18 months $(47 \%, \mathrm{p}<0.05)$ and 24 months (55\%, $\mathrm{p}<0.05$ ) were observed (Fig. 4).

Given that lipid peroxidation is widely accepted as a sign of oxidative stress, we used lipid peroxides content, expressed as TBARS, to determine the degree of lipid peroxidation. Our data revealed significantly low levels of peroxidation in the 1.5-month-old group $(29 \%, p<0.05)$, whereas higher levels were detected at 18 and 24 months of age (35\% for both groups of rats,

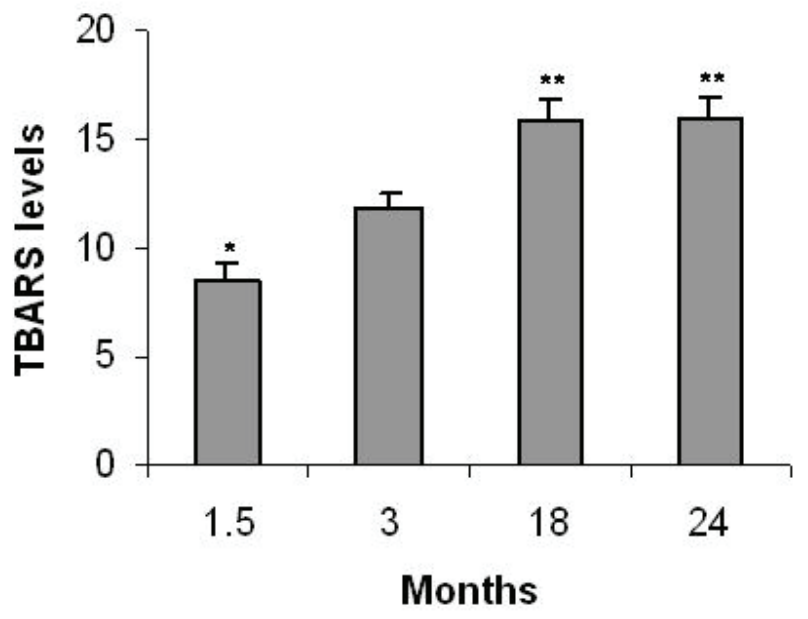

Fig. 5. Effects of aging (1.5 - 24 months) on thiobarbituric reactive substances (TBARS) levels in rat liver. Results are expressed as ng TBARS/mg protein. Values are shown as mean \pm S.E.M. ( $n=6$ per group). ${ }^{*} p<0.05,{ }^{* *} p<0.01$ vs. 3 -month-old group.

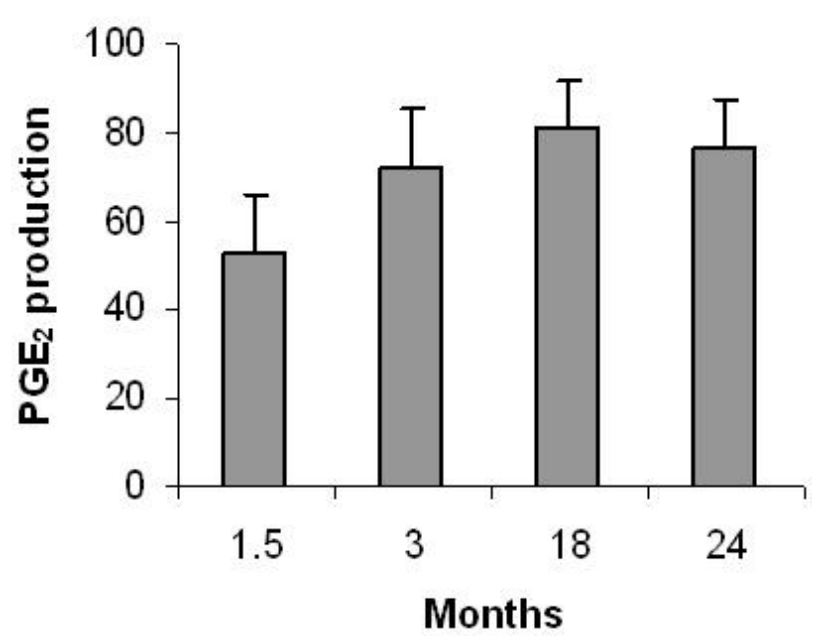

Fig. 6. Effects of aging (1.5 - 24 months) on prostaglandin $E_{2}$ $\left(\mathrm{PGE}_{2}\right)$ production in rat liver. Results are expressed as $\mathrm{pg} / \mathrm{mg}$ protein. Values are shown as mean \pm S.E.M. ( $n=6$ per group).

$\mathrm{p}<0.01$ ) than in the 3-month-old rats (Fig. 5). NO showed a significant negative correlation with TBARS $(\mathrm{r}=-0.9902, \mathrm{p}<0.01)$.

$\mathrm{PGE}_{2}$ production did not change significantly throughout the aging process (Fig. 6) which contributed to the hepatoprotective function of $\mathrm{PGE}_{2}$ in aged animals.

It has been reported that mitochondria are the main source of ROS and hence of oxidative stress. On the basis of this observation, we determined the content of nucleotides and their metabolites during aging. No alteration was observed in any of the parameters studied during aging (Fig. 7). 
aNUCLEOTIDES, aNUCLEOSIDES, aBASES

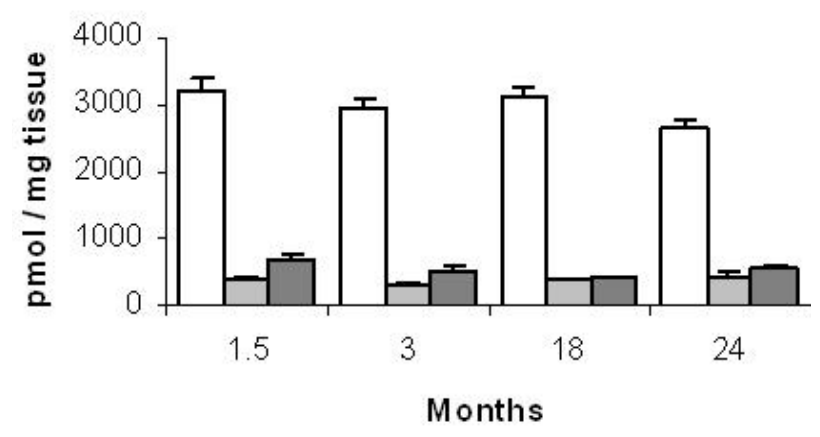

Fig. 7. Effects of aging (1.5 - 24 months) on adenosine nucleotides (ATP, ADP and AMP), nucleosides (adenosine and inosine), and purine bases (xanthine and hypoxanthine) content in rat liver. Results are expressed as $\mathrm{pmol} / \mathrm{mg}$ tissue. Values are shown as mean \pm S.E.M. ( $n=6$ per group $)$.

\section{Discussion}

Appropriate levels of $\mathrm{O}_{2}^{-}$, the first $\mathrm{ROS}$ generated, are maintained by SOD in order to prevent the cascade of events that gives rise to oxidative stress, which is known to play a crucial role in regulating the activity and lifespan of many species (Orr and Sohal 1994, Cutler 1995, Orr and Sohal 2003). At 1.5 months of age a decrease in SOD was observed together with a simultaneous increase in $\mathrm{O}_{2}^{-}$production, thereby indicating oxidative stress at this age. The increase in $\mathrm{O}_{2}{ }^{-}$ production was related to low levels of SOD, which may be a consequence of rat immaturity at this age; similar results were observed by Jung and Henke (1996) and this observation is attributed to developmental changes. The slight improvement in $\mathrm{O}_{2}^{-}$production at 18 months of age compared to 24 months of age confirm in liver the findings observed in rat aorta and gastrointestinal tract (Marmol et al. 2007, 2009). This improvement can be attributed to a greater susceptibility of the 18-month-old group to oxidative stress than the oldest rats. These results are consistent with the observations, in very old mice, in which immunological parameters were more similar in adult mice than aged ones (Puerto et al. 2005). Similar results were obtained in rat brain and were attributed to hormonal alterations (andropause) at this age (Ehrenbrink et al. 2006).

The observation that the antioxidant enzymes assayed (SOD and catalase) remained constant in the aged animals is consistent with the data that do not demonstrate any alteration in the levels of antioxidant enzymes in the liver of aged rats (Cand and Verdetti
1989, Semsei et al. 1989, Barja de Quiroga et al. 1990, Santa Maria et al. 1996, Dogru-Abbasoglu et al. 1997).

The observed resistance to lipid peroxidation, expressed as TBARS, at 1.5 months of age could be due to the low availability of substrate and a high cholesterol/ phospholipid ratio (Devasagayam 1986). The increase in lipid peroxides at 18 and 24 months of age reflects oxidative stress in both groups. However, this condition was not associated with changes in antioxidant enzyme activity. Nevertheless, this increase in lipid peroxides in the oldest groups of rats (18 and 24 months) may be related to the significant antioxidant activity of $\mathrm{NO}$ (Hummel et al. 2006). The decrease in NO at 18 and 24 months of age and hence a decrease in antioxidant activity could explain the increase in lipid peroxides observed at these ages. The significant negative correlation between $\mathrm{NO}$ and TBARS supports the mechanisms proposed. The significant increase in NO at 1.5 months of age may be related to the immaturity of the rats and should be interpreted as beneficial because of its cytoprotective action (Suzuki et al. 1995, Farzaneh-Far and Moore 2001). In contrast the significant decrease in NO observed at 18 and 24 months of age is a contributory factor to aging (Di Massimo et al. 2006) and has previously been related to a decrease in the endogenous substrate L-arginine (Reckelhoff et al. 1994).

Our results show similar production of $\mathrm{PGE}_{2}$ at $1.5,3,18$ and 24 months, thereby indicating no changes in its protective role in the liver. Furthermore, the $\mathrm{PGE}_{2}$ production observed in aging rats indicate that the liver is more resistant than other organs to the pro-inflammatory status. These findings also indicate that there is no relationship between oxidative stress and inflammatory parameters in aged animals.

Given that mitochondrial respiration is essential for the production of ATP, damage to mitochondria as a result of oxidative stress could result in reduced energy production and compromised cell function. It is currently unclear whether in vitro studies of oxidative damage to mitochondria are an accurate indication of what occurs in vivo. The question of whether the accumulation of oxidative damage under normal physiological conditions in vivo leads to mitochondria dysfunction and increased generation of ROS remains to be answered (Van Remmen and Richardson 2001). Recently has questioned the commonly accepted idea that ROS generation by the mitochondrial respiratory chain is the main source of ROS involved in aging (Krause 2007). In this regard ultrastructural analysis of the human liver has shown that 
the integrity of mitochondria and enzymatic activity and ATP content and production remain mostly unchanged with aging (Anantharaju et al. 2002, Drew and Leeuwenburgh 2003). Our results corroborate these findings and no alteration in the levels of nucleotides or their metabolites was observed during aging. This may be related to the fact that the levels of oxidative stress were not sufficient to alter liver function.

In conclusion, our results demonstrate a significant decrease in the levels of NO in the older groups of rats and hence in its antioxidant activity. This could explain the observed increase in lipid peroxides in these groups of rats, and therefore suggests an important role for NO in oxidative stress in the liver of older rats.

\section{Conflict of Interest}

There is no conflict of interest.

\section{Acknowledgements}

This paper was supported by the FIS PI 05/2629. We are grateful to Robin Rycroft for valuable assistance in the preparation of the manuscript.

\section{References}

AEBI H: Catalase in vitro. Methods Enzymol 105: 121-126, 1984.

ANANTHARAJU A, FELLER A, CHEDID A: Aging liver. Gerontology 48: 343-353, 2002.

BARJA DE QUIROGA G, PEREZ-CAMPO R, LOPEZ-TORRES M: Anti-oxidant defences and peroxidation in liver and brain of aged rats. Biochem J 272: 247-250, 1990.

CAND F, VERDETTI J: Superoxide dismutase, glutathione peroxidase, catalase, and lipid peroxidation in the major organs of the aging rats. Free Radic Biol Med 7: 59-63, 1989.

CUTLER RG: Oxidative stress: its potential relevance to human disease and longevity determinants. Age 18: 91-96, 1995.

DE MINICIS S, BATALLER R, BRENNER DA: NADPH oxidase in the liver: defensive, offensive, or fibrogenic? Gastroenterology 131: 272-275, 2006.

DEVASAGAYAM TP: Low level of lipid peroxidation in newborn rats. Possible factors for resistance in hepatic microsomes. FEBS Lett 199: 203-207, 1986.

DI MASSIMO C, SCARPELLI P, DI LORENZO N, CAIMI G, DI ORIO F, CIANCARELLI MGT: Impaired plasma nitric oxide availability and extracellular superoxide dismutase activity in healthy humans with advancing age. Life Sci 78: 1163-1167, 2006.

DOGRU-ABBASOGLU S, TAMER-TOPTANI S, UGURNAL B, KOCAK-TOKER N, AYKAC-TOKER G, UYSAL, M: Lipid peroxidation and antioxidant enzymes in livers and brains of aged rats. Mech Ageing Dev 98: 177 180, 1997.

DREW B, LEEUWENBURGH CH: Method for measuring ATP production in isolated mitochondria: ATP production in brain and liver mitochondria of Fischer-344 rats with age and caloric restriction. Am J Physiol 285: R1259R1267, 2003.

EHRENBRINK G, SCHÄFER F, BOEIRA T, PILLA A, RODRIGUES M, SILVEIRA M: Antioxidant enzymes activities and protein damage in rat brain of both sexes. Exp Gerontol 41: 368-371, 2006.

FARACI FM, DIDION SP: Vascular protection - superoxide dismutase isoforms in the vessel wall. Arterioscler Thromb Vasc Biol 24: 1367-1373, 2004.

FARZANEH-FAR R, MOORE K: Nitric oxide and the liver. Liver 21: 161-174, 2001.

GUDKOV SV, SHTARKMAN IN, SMIRNOVA VS, CHERNIKOV AV, BRUSKOV VI: Guanosine and inosine display antioxidant activity, protect DNA in vitro from oxidative damage induced by reactive oxygen species, and serve as radioprotectors in mice. Radiat Res 165: 538-545, 2006.

HARPER ME, BEVILACQUA L, HAGOPIAN K, WEINDRUCH R, RAMSEY JJ: Ageing, oxidative stress, and mitochondrial uncoupling. Acta Physiol Scand 182: 321-331, 2004.

HOSSAIN MA, WAKABAYASHI H, IZUISHI K, OKANO K, YACHIDA S, MAETA H: The role of prostaglandins in liver ischemia-reperfusion injury. Curr Pharm Des 12: 2935-2951, 2006.

HUMMEL SG, FISCHER AJ, MARTIN SM, SCHAFER FQ, BUETTNER GR: Nitric oxide as a cellular antioxidant: A little goes a long way. Free Radic Biol Med 40: 501-506, 2006. 
JAESCHKE H: Reactive oxygen and mechanisms of inflammatory liver injury. $J$ Gastroenterol Hepatol 15: 718-724, 2000.

JUNG K, HENKE W: Developmental changes of antioxidant enzymes in kidney and liver from rats. Free Radic Biol Med 20: 613-617, 1996.

KRAUSE KH: Aging: A revisited theory based on free radicals generated by NOX family NADPH oxidases. Exp Gerontol 42: 256-262, 2007.

LOWRY OH, ROSEBROUGH NJ, FARR AL, RANDALL RJ: Protein measurement with the Folin phenol regeant. J Biol Chem 193: 265-275, 1951.

MARKLUND L: Pyrogallol autooxidation. In: Handbook of Methods for Oxygen Radical Research. GREENWALD RA (ed), CRC Press, Boca Raton, 1985, pp 243-247.

MARMOL F, SANCHEZ J, LOPEZ D, MARTINEZ N, ROSELLÓ-CATAFAU J, MITJAVILA MT, PUIGPARELLADA P: Loss of adaptation to oxidative stress as a mechanism for aortic damage in aging rats. J Physiol Biochem 63: 239-248, 2007.

MARMOL F, SANCHEZ J, LOPEZ D, MARTINEZ N, MITJAVILA MT, PUIG-PARELLADA P: Oxidative stress, nitric oxide and prostaglandin $\mathrm{E}_{2}$ levels in the gastrointestinal tract of aging rats. $J$ Pharm Pharmacol 61: 201206, 2009.

MIQUEL J, ECONOMOS AC, FLEMING J, JOHNSON JE: Mitochondrial role in cell aging. Exp Gerontol 15: 579$591,1980$.

ORR WC, SOHAL RS: Extension of life-span by overexpression of superoxide dismutase and catalase in Drosophila melanogaster. Science 263: 1128-1130, 1994.

ORR WC, SOHAL RS: Does overexpression of $\mathrm{Cu}, \mathrm{Zn}-\mathrm{SOD}$ extend life span in Drosophila melanogaster? Exp Gerontol 38: 227-230, 2003.

PAGANO PJ, ITO Y, TORNHEIM K, GALLOP PM, TAUBER AI, COHEN RA: An NADPH oxidase superoxidegenerating system in the rabbit aorta. Am J Physiol 268: H2274-H2280, 1995.

PARK SW, UENO R, HAYAISHI O: Prostaglandin synthesizing enzyme activities of hepatocytes and non-hepatocytes in rat liver as a function of age. Biochem Int 13: 827-834, 1986.

PIEPER GM, JORDAN M, DONDLINGER LA, ADAMS MB, ROZA AM: Peroxidative stress in diabetic blood vessels. Reversal by pancreatic islet transplantation. Diabetes 44: 884-889, 1995.

PUERTO M, GUAYERBAS N, ALVAREZ P, DE LA FUENTE M: Modulation of neuropeptide Y and norepinephrine on several leucocyte functions in adult, old and very old mice. J Neuroimmunol 165: 33-40, 2005.

RECKELHOFF JF, KELLUM JA, BLANCHARD EJ, BACON EE, WESLEY AJ, KRUCKEBERG WC: Changes in nitric oxide precursor, L-arginine, and metabolites, nitrate and nitrite, with aging. Life Sci 55: 1895-1902, 1994.

SANTA MARIA C, AYALA A, REVILLA E: Changes in superoxide dismutase activity in liver and lung of old rats. Free Radic Res 25: 401-405, 1996.

SCHNEIDER L, PLETSCHMANN M, HARTWIG W, SEVILLANO S, HACKERT T, GEBHARD MM, UHL W, BUCHLER MW, WERNER J: Inosine reduces microcirculatory disturbance and inflammatory organ damage in experimental acute pancreatitis in rats. Am J Surg 191: 510-514, 2006.

SEMSEI I, RAO G, RICHARDSON A: Changes in the expression of superoxide dismutase and catalase as a function of age and dietary restriction. Biochem Biophys Res Commun 164: 620-625, 1989.

SOHAL RS: Role of oxidative stress and protein oxidation in the aging process. Free Radic Biol Med 33: 37-44, 2002.

SUZUKI H, MENEGAZZI M, CARCERI DE PRATI A, MARIOTTO S, ARMATO U: Nitric oxide in the liver: physiopathological roles. Adv Neuroimmunol 5: 379-410, 1995.

VAN REMMEN H, RICHARDSON A: Oxidative damage to mitochondria and aging. Exp Gerontol 36: 957-968, 2001. VANIN AF: Iron diethyldithiocarbamate as spin trap for nitric oxide detection. Meth Enzymol 301: 269-279, 1999. 